\title{
PENGARUH MINYAK CUMI PADA UMPAN BUBU DASAR TERHADAP HASIL TANGKAPAN IKAN-IKAN KARANG
}

\author{
Emil Reppie \\ Staf Pengajar pada Program Studi Pemanfaatan Sumberdaya Perikanan, \\ Fakultas Perikanan dan IImu Kelautan UNSRAT, Manado, 95115.
}

\begin{abstract}
Bottom trap have been used widely by coastal communities in North Sulawesi to catch coral fishes, since it simple in design, cheaper and easier to manage with a small boat. Unfortunately, the fishing practice of the traditional trap is usually conducted in destructive way, where fishermen cover the gear with live coral to attract fishing target. Although the gear's design has evolved over centuries, there is still potential for improving its catching efficiency and selectivity. An attempt to understand the fishing process of bottom trap should therefore be focused on bait and how its chemical composition, visual and physical properties may stimulate target species to attack the bait and captured. Addition of squid liver oil to the bait could increase the fishing power of bottom trap gear. But scientific information's about its applications are not available yet. Therefore, the objective of this research was to study the effect of squid liver oil on bait of bottom trap toward the capture of coral fishes. This research was done in Bangka Strait North of Minahasa, based on experimental method. Six units of bottom trap (bamboo) were operated ten nights in collecting data; three units using scad mackerel bait that injected by squid liver oil, and tree other units using scad mackerel bait without squid liver oil. The capture data were analyzed by $t_{\text {test }}$. The catch was 117 fish in total consist of 2 genera; 74 fish was caught by scad mackerel bait with squid liver oil, and 43 fish was caught by bait without squid liver oil. Analysis of $t_{\text {test }}$ show that $t_{0}=8.908>t 0.05 ; 5=3.250$; which means that the addition of squid liver oil on bait could increase the catch of bottom trap.
\end{abstract}

Key words: Bottom trap, squid liver oil, baits, coral fishes.

\section{PENDAHULUAN}

Bubu dasar merupakan salah satu alat tangkap yang umum digunakan oleh masyarakat nelayan untuk menangkap ikan-ikan karang, karena konstruksinya sederhana, relatif murah dan mudah dioperasikan dengan kapal atau perahu ukuran kecil. Sayangnya, praktek pengoperasian bubu tradisional biasanya bersifat merusak, dimana nelayan menutup alat tangkap dengan patahan karang hidup untuk menarik ikan target. Walaupun alat tangkap ini telah berkembang sejak lama, tetapi efisiensi penangkapan ikan dan selektivitasnya masih memiliki potensi pengembangan untuk memenuhi kriteria ramah lingkungan dan berkelanjutan.

Keberhasilan alat tangkap berumpan sangat ditentukan oleh aktivitas hidup ikan dalam hal mencari dan menangkap makanan. Pengetahuan yang diperoleh melalui studi-studi tentang tingkah laku ikan mengambil makanan, akan sangat membantu untuk memahami interaksi spesies target dengan alat tangkap berumpan (Lokkeborg, 1994). Selanjutnya, batas respon ikan target terhadap bau umpan (bait odour) juga ditentukan oleh besarnya active space dimana tingkah laku food-searching berlangsung. Studi tingkah laku menunjukan bahwa sablefish (Anoplopoma fimbria) sangat sensitif terhadap bau umpan; dan dalam perhitungan mengindikasikan bahwa panjang maksimum active space dimana sablefish meperlihatkan respon foodsearching, dapat mencapai beberapa kilometer. Kalkulasi demikian, memerlukan teknik-teknik dengan memperhatikan tingkat pelepasan bau umpan, dispersi spasial atraktan, batas respon ikan dan faktorfaktor lain yang mempengaruhi active space untuk food-searching. 
Ikan juga menjadi tertarik pada umpan melalui penglihatan; tetapi karena visibility dalam air terbatas (Guthrie dan Muntz, 1993), maka rangsangan visual terhadap kehadiran umpan hanya berperan ketika ikan telah berada dekat dengan alat tangkap berumpan. Rangsangan olfactory sering diikuti oleh orientasi rheotactic untuk melokalisir sumber kimia (Atema, 1980). Ikan cod yang berenang searah arus akan berbalik dan berenang ke atas arus ketika berespon pada ekstrak makanan dalam tangki percobaan (Pawson, 1977). Pengamatan pada ikan cod dan haddock di lingkungan alami, menunjukan bahwa ikan yang berespon pada pancing berumpan lebih sering berenang ke atas arus, dibandingkan dengan ikan yang tidak berespon, dan hal ini mengindikasikan orientasi rheotactic.

Respon ikan terhadap umpan dipengaruhi baik oleh arus lemah maupun arus kuat; pengamatan lapang tentang tingkah laku ikan whiting (Gadus merlangus) terhadap pancing berumpan, menunjukan bahwa aktivitas ikan lebih besar pada saat berarus daripada tidak berarus (Ferno, et. al., 1986). Lebih banyak ikan tertarik pada umpan saat berarus karena stimuli olfactory terbawa lebih jauh. Namun terdapat sejumlah kecil ikan yang terkena respon tidak bereaksi karena mungkin lemahnya pedoman arah. Sebaliknya, respon ikan terhadap pancing berumpan juga akan berkurang ketika arus kuat; kemungkinan berkaitan dengan optimisasi energi.

Fokus utama untuk memahami proses tertangkapnya ikan adalah tertuju pada umpan dan bagaimana komposisi kimianya yang merangsang ikan untuk makan; kemudian penglihatan dan penampilan fisik yang dapat menstimulasi respon positif atau negatif terhadap alat tangkap. Pemberian ekstrak berupa minyak cumi pada umpan, diduga dapat meningkatkan fishing power dari alat tangkap bubu dasar. Namun informasi ilmiah seperti ini, khususnya pada ikanikan karang, belum banyak tersedia dan bahkan masih sulit diperoleh. Oleh karena itu, tujuan penelitian ini adalah untuk mempelajari pengaruh minyak cumi pada umpan bubu dasar terhadap hasil tangkapan ikanikan karang; dan mengidentifikasi jenisjenis ikan yang tertangkap.

\section{METODOLOGI PENELITIAN}

Penelitian ini dilakukan di perairan Selat Bangka Kabupaten Minahasa Utara Propinsi Sulawesi Utara, pada bulan JuliAgustus 2010; yang didasarkan pada metode eksperimental (Nasir, 1999). Bahan dan alat yang digunakan terdiri dari: alat tangkap bubu 6 unit, perahu bermotor 1 unit, umpan ikan malalugis (Decapterus macarellus) 60 ekor, larutan minyak cumi 1 botol, bahan bakar bensin dan oli, 2 buah alat suntik ekstrak dan alat tulis menulis.

Alat tangkap bubu yang digunakan terbuat dari bambu dengan kerangka besi, berdimensi $120 \times 60 \times 30 \mathrm{~cm}$ dan pintu masuk terbuat dari jaring $\mathrm{PE} 380 \times \mathrm{D} / 12$, ukuran mata 1,25 inci. Tiga unit bubu menggunakan umpan malalugis yang diberikan atau disuntikan larutan minyak cumi; sedangkan 3 unit bubu lainnya menggunakan umpan malalugis tanpa larutan minyak cumi. Alat tangkap yang telah berumpan diturunkan sore hari di dasar perairan pada kedalaman sekitar 15-20 m, dibiarkan semalam kemudian diangkat pada besok paginya. Jarak penempatan tiap unit bubu diupayakan cukup berjauhan untuk menghindari saling interaksi. Pengoperasian bubu dilakukan sebanyak 10 trip pada saat bulan gelap. Hasil tangkapan dicatat dan diidentifikasi berdasarkan perlakuan dan trip operasi.

Untuk memenuhi persyaratan analisis dalam menarik kesimpulan, maka dirumuskan hipotesis sebagai berikut:

$\mathrm{H}_{0}=$ Penggunaan larutan minyak cumi pada umpan bubu dasar, tidak berpengaruh terhadap hasil tangkapan;

$\mathrm{H}_{1}=$ Penggunaan larutan minyak cumi pada umpan bubu dasar, berpengaruh terhadap hasil tangkapan;

dimana:

$\mathrm{H}_{0}$ diterima $\left(\mathrm{H}_{1}\right.$ ditolak $)$ apabila $\mathrm{T}_{0} \leq \mathrm{T}_{\mathrm{t}}$

$\mathrm{H}_{0}$ ditolak $\left(\mathrm{H}_{1}\right.$ diterima) apabila $\mathrm{T}_{0}>\mathrm{T}_{\mathrm{t}}$.

Selanjutnya $T_{0}$ dihitung menggunakan analisis komparatif 2 sampel berkorelasi (Hasan, 2004), dengan rumusan:

$$
T_{0}=\frac{\bar{X}-\bar{Y}}{\sqrt{\frac{\sum D^{2}-\frac{\left(\sum D\right)^{2}}{n}}{n(n-1)}}}
$$


Pengaruh Minyak Cumi Pada Umpan Bubu Dasar

\section{HASIL DAN PEMBAHASAN}

Hasil tangkapan bubu dasar selama penelitian berjumlah 117 ekor, sebanyak 74 ekor tertangkap dengan umpan berekstrak minyak cumi dan 43 ekor tertangkap dengan umpan tanpa ekstrak minyak cumi (Tabel 1). Jenis-jenis ikan yang tertangkap terdiri dari 21 genus (Tabel 2).

Tabel 1. Jumlah hasil tangkapan (ekor) bubu dasar menurut perlakuan.

\begin{tabular}{|c|c|c|c|c|c|c|c|c|}
\hline \multirow[t]{2}{*}{ Trip } & \multicolumn{4}{|c|}{$\begin{array}{c}\text { Umpan berekstrak } \\
\text { cumi }\end{array}$} & \multicolumn{4}{|c|}{$\begin{array}{c}\text { Umpan tanpa ekstrak } \\
\text { cumi }\end{array}$} \\
\hline & 1 & 2 & 3 & Total & 1 & 2 & 3 & Total \\
\hline 1 & 2 & 2 & 3 & 7 & 1 & 1 & 1 & 3 \\
\hline 2 & 3 & 3 & 2 & 8 & 2 & 2 & 1 & 5 \\
\hline 3 & 3 & 4 & 4 & 11 & 2 & 2 & 2 & 6 \\
\hline 4 & 3 & 2 & 2 & 7 & 1 & 1 & 2 & 4 \\
\hline 5 & 3 & 3 & 4 & 10 & 3 & 2 & 1 & 6 \\
\hline 6 & 3 & 4 & 2 & 9 & 1 & 2 & 2 & 5 \\
\hline 7 & 2 & 1 & 2 & 5 & 1 & 1 & 1 & 3 \\
\hline 8 & 2 & 2 & 2 & 6 & 1 & 1 & 2 & 4 \\
\hline 9 & 2 & 2 & 1 & 5 & 1 & 1 & 1 & 3 \\
\hline 10 & 2 & 2 & 2 & 6 & 2 & 1 & 1 & 4 \\
\hline Total & 25 & 25 & 24 & 74 & 15 & 14 & 14 & 43 \\
\hline Rataan & 2,5 & 2,5 & 2,4 & 7,4 & 1,5 & 1,4 & 1,4 & 4,3 \\
\hline
\end{tabular}

Tabel 2. Jenis-jenis ikan yang tertangkap berdasarkan perlakuan (ekor)

\begin{tabular}{rllrrr}
\hline No & \multicolumn{1}{c}{$\begin{array}{c}\text { Nama genus dan } \\
\text { spesies }\end{array}$} & $\begin{array}{c}\text { Nama } \\
\text { lokal }\end{array}$ & $\begin{array}{r}\text { Ber- } \\
\text { ektrak }\end{array}$ & $\begin{array}{r}\text { Tanpa } \\
\text { ekstrak }\end{array}$ & Total \\
\hline 1 & Cephalopholis sp & Kerapu & 7 & 5 & 12 \\
2 & Epinephelus sp. & Kerapu & 7 & 3 & 10 \\
3 & Plectropomus leopardus & Kerapu & 2 & 1 & 3 \\
4 & Lethrinus sp. & Lencam & 2 & 2 & 4 \\
5 & Gymnocranius grandoculus & Lencam & 3 & 1 & 4 \\
6 & Zebrasoma scopas & Bobaralao & 4 & 2 & 6 \\
7 & Stenochaetus striatus & Bobaralao & 3 & 2 & 5 \\
8 & Siganus sp. & Beronang & 8 & 5 & 13 \\
9 & Plectorchinchus lessoni & Rajabao & 3 & 2 & 5 \\
10 & Balistoides viridescens & Triger & 2 & 1 & 3 \\
11 & Balistapus undulatus & Triger & 3 & 2 & 5 \\
12 & Odonus niger (101-3) & Triger biru & 4 & 1 & 5 \\
13 & Sufflamen fraenatus & Triger & 3 & 2 & 5 \\
14 & Parupeneus multifasciatus & Biji nangka & 3 & 2 & 5 \\
15 & Cheilinus sp. & Maming & 3 & 4 & 7 \\
16 & Halichoeres hortulanus & Maming & 1 & 2 & 3 \\
17 & Zanclus cornutus & Gayaman & 3 & 1 & 4 \\
18 & Chaetodon kleinii & Kupu-kupu & 2 & 1 & 3 \\
19 & Portunus pelagicus & Kepiting & 3 & 2 & 5 \\
20 & Amblyglyphidodon curacao & Luku & 3 & 2 & 5 \\
21 & Abudefduf vaigiensis & Sersan mayor & 3 & 2 & 5 \\
\hline Jumlah Individu & & 72 & 45 & 117 \\
\hline
\end{tabular}

Untuk menguji hipotesis yang telah ditetapkan sebelumnya, maka uji T menggunakan analisis komparatif dua sampel berkorelasi dikerjakan seperti berikut:

$$
\left(\sum D\right)^{2}=961 \quad \sum D^{2}=107
$$

Taraf nyata $(\alpha)=1 \%(0,01)$

Nilai $T$ tabel dengan derajat bebas $(\mathrm{db})=\mathrm{n}-1=9$.

$\mathrm{T}_{0,01 ; 9}=3,250$ (nilai pada tabel).
Tabel 5. Analisis komparatif dua sampel berkorelasi terhadap hasil tangkapan bubu dasar berdasarkan perlakuan

\begin{tabular}{rccrr} 
No. & $\begin{array}{c}\text { Berekstrak } \\
(\mathbf{X})\end{array}$ & $\begin{array}{c}\text { Tanpa ekstrak } \\
(\mathbf{Y})\end{array}$ & $\begin{array}{c}\mathbf{D} \\
(\mathbf{X}-\mathbf{Y})\end{array}$ & $\mathbf{D}^{2}$ \\
\hline 1 & 7,0 & 3,0 & 4 & 16 \\
2 & 8,0 & 5,0 & 3 & 9 \\
3 & 11,0 & 6,0 & 5 & 25 \\
4 & 7,0 & 4,0 & 3 & 9 \\
5 & 10,0 & 6,0 & 4 & 16 \\
6 & 9,0 & 5,0 & 4 & 16 \\
7 & 5,0 & 3,0 & 2 & 4 \\
8 & 6,0 & 4,0 & 2 & 4 \\
9 & 5,0 & 3,0 & 2 & 4 \\
10 & 6,0 & $\mathbf{4 , 0}$ & 2 & 4 \\
Jumlah & $\mathbf{7 4 , 0}$ & $\mathbf{4 3 , 0}$ & $\mathbf{3 1}$ & $\mathbf{1 0 7}$ \\
\hline Rataan & $\mathbf{7 , 4}$ & $\mathbf{4 , 3}$ & & \\
\hline
\end{tabular}

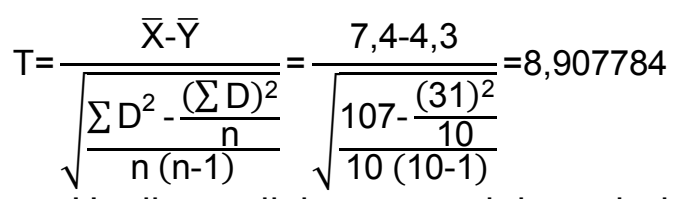

Hasil analisis menunjukan bahwa $\mathrm{T}_{0}=8,908>\mathrm{T}_{0,01 ; 9}=3,250$; sehingga menolak $\mathrm{H}_{0}$ dan menerima $\mathrm{H}_{1}$, dimana hal ini ini menjelasan bahwa penggunaan larutan minyak cumi pada umpan bubu dasar, berpengaruh terhadap hasil tangkapan.

Tingkah laku ikan terhadap alat tangkap berumpan seperti bubu dasar yang digunakan dalam penelitian ini, sangat dipengaruhi oleh umpan itu sendiri selama proses tertangkapnya ikan. Ketika ikan menyadari atau terangsang dengan kehadiran umpan, maka ikan akan berupaya mencari posisi sumber rangsangan; dan ketika menemukan sumber rangsangan, ikan akan menyerang umpan; kemudian respon diakhiri dengan masuk ke bubu untuk menelan umpan dan ikan tertangkap; atau menolak masuk ke bubu sehingga ikan tidak tertangkap.

Studi-studi tentang pemberian rangsangan kimiawi pada umpan, telah dilakukan sejak lama oleh beberapa ahli (Labaro, dkk., 2008); antara lain Tester, Yuen dan Takeda (1954) dalam Gunarso (1985), yang mencoba menarik perhatian ikan dengan menggunakan aroma bau pada perikanan long line. Kemudian Kuroki (1969) dalam Gunarso (1985), juga telah melakukan percobaan sejumlah umpan buatan dari nilon yang dicelup ke dalam minyak cumi-cumi dan diperlakukan pada perikanan long line. Namun hasilnya masih belum memuaskan sehingga belum dapat diterapkan pada perikanan komersial. Teknik pemberian mi- 
nyak cumi pada umpan untuk bubu ternyata memberikan hasil yang lebih baik daripada umpan yang sama tanpa ekstrak cumi. Sehingga layak diterapkan pada masyarakat nelayan bubu yang bisanya menutup alat tangkap dengan karang hidup.

\section{KESIMPULAN}

Penggunaan larutan minyak cumi pada umpan bubu dasar, berpengaruh terhadap hasil tangkapan. Ikan-ikan yang tertangkap umumnya didominasi oleh jenisjenis ikan karang. Metode penangkapan ikan ini layak diterapkan pada masyarakat nelayan, terutama yang biasa menggunakan karang hidup untuk menutup atau menyamarkan alat tangkap bubu sebagai shelter.

\section{DAFTAR PUSTAKA}

Atema, J. 1980. Chemical senses, chemical signals and feeding behaviour in fishes. In: Fish behaviour and its use in the capture and culture of fishes. Pp. 57-101. ICLARM conf. Proc. 5 Manila.

Ferno A, Solemdal P, Tilseth S. 1986. Field studies on the behaviour of whiting (Gadus merlangus) toward baited hooks. Fisk Dir. Ser. Hav. Unders. 18, 83-95.
Gunarso W. 1985. Suatu pengantar tentang tingkah laku ikan terutama dalam hubungannya dengan alat, metode dan taktik penangkapan. Fakultas Perikanan Institut Pertanian Bogor. 142 hal.

Guthrie, DM, Muntz WRA. 1993. Role of vision in fish behaviour. In: Behaviour of teleost fishes. (eds Pitcher TJ.) 89-128. Chapman and Hall, London.

Hasan, I. 2004. Analisis data penelitian dengan statistik. PT. Bumi Aksara. Jakarta. 220 hal.

Labaro L, Katiandagho EM, Reppie E, dan Budiman J. 2008. Pengaruh larutan minyak cumi terhadap hasil tangkapan pancing ulur tuna di perairan sekitar Pulau Batang Dua. Prosiding Konferensi Nasional VI, Pengelolaan Sumberdaya Pesisir dan Lautan, 2008. ISBN: 978-979-25-23478.Hal.782-790.

Lokkeborg S. 1994. Fish behaviour and long line. In: Marine fish behaviour in capture adn abundance estimation, (9-27). Fishing News Books.

Nasir M. 1999. Meode penelitian (Cetakan keempat). Ghalia Indonesia. 622 hal

Pawson MG. 1977. The responses of cod (Gadus morhua) to chemical attractants in moving water. J. Cons. Int. Explor. 37(3), 316-18. 